\title{
Making Energy Savings by the Engagement of Small and Medium-sized Enterprise on Energy Management
}

\author{
Isaac Ayebah Adams ${ }^{1}$, Samuel Gyamfi ${ }^{1}$, Christian Kwaku Amuzuvi ${ }^{2,}$ * \\ ${ }^{1}$ Department of Energy and Petroleum Engineering, University of Energy and Natural Resources, Sunyani, Ghana \\ ${ }^{2}$ Department of Renewable Energy Engineering, University of Mines and Technology, Tarkwa, Ghana
}

Email address:

samuel.gyamfi@uenr.edu.gh (S. Gyamfi), ckamuzuvi@umat.edu.gh (C. K. Amuzuvi)

${ }^{*}$ Corresponding author

\section{To cite this article:}

Isaac Ayebah Adams, Samuel Gyamfi, Christian Kwaku Amuzuvi. Making Energy Savings by the Engagement of Small and Medium-sized Enterprise on Energy Management. Journal of Electrical and Electronic Engineering. Vol. 9, No. 2, 2021, pp. 41-48.

doi: $10.11648 /$ j.jeee.20210902.12

Received: November 23, 2020; Accepted: March 16, 2021; Published: May 8, 2021

\begin{abstract}
Small and medium-sized enterprises (SMEs) are crucial in every economy, comprising ninety-nine percent (99\%) of enterprises and providing about sixty percent $(60 \%)$ of employment. They contribute about fifty percent $(50 \%)$ of global gross value addition and between sixteen percent $(16 \%)$ to about eighty percent $(80 \%)$ of gross domestic product (IEA, 2015). Individual SMEs use small amounts of energy, but their collective energy demand is considerable. The International Energy Agency (IEA) estimates SMEs to consume more than thirteen (13\%) of total global energy demand i.e. about 74 exajoules (EJ). Effective energy efficiency measures can save as much as $30 \%$ of consumption, namely $22 \mathrm{EJ}$, which is more than the energy used by Japan and Korea per year (IEA, 2015). Therefore, the increase in energy efficiency offers a substantial value for economies, societies and SMEs. This research looks at how SMEs in the Sunyani Municipality take seriously their energy consumption and how energy management can help reduce energy cost through efficiency improvement and increase profitability and growth of their businesses. The study was designed into two forms. Firstly, the energy use practices of the SMEs were investigated. Secondly, the study applied energy auditing method to identify energy reduction strategies that can help reduce the energy consumption of the SMEs. The results reveal that, majority of energy consumers in SMEs do not pay attention to their energy consumption patterns as indicated by $92 \%$ of the respondents interviewed. The increase in energy consumption among SMEs could be attributable to the increase in electricity bills. The energy audit identified energy conservation opportunities that can help reduce energy usage in the various SMEs such as switching from CFL and T12 lamps to LED bulbs, replacing old refrigerators, hair driers and industrial irons with more efficient ones, and replacing worn out equipment with high energy efficient ones. The study recommends the use of public education in a paradigm shift from the use of old appliances to new ones in order to save energy and cost.
\end{abstract}

Keywords: Small and Medium-Sized Enterprises, Energy Audit, Energy Efficiency

\section{Introduction}

SMEs play important roles in the economy of both developed and developing countries and contributes to growth of industry and the creation of jobs for its citizens. They encourage private ownership and builds entrepreneurial skills. They also foster economic growth, generate employment, contribute to development of a dynamic private sector and make a significant contribution to exports and trade.

The International Energy Agency (IEA) estimated that,
SMEs share of energy demand account for at least $13 \%$ of the global final energy consumption annually, yet their ramifications on energy and the environment is relatively understudied. They are rarely the subject of government policy, dismissed for being 'too difficult' to reach [1].

According to the International Energy Agency [2], there is a huge energy savings potential in SMEs and that, energy efficiency can help SMEs to cut cost. Energy efficiency in SMEs contributes to broader benefits to societies by reducing reliance on energy imports and need for investments in additional generation capacity. It will also lower 
environmental impacts such as Green House Gas (GHG) emissions and local air pollution [2]. The importance of SMEs is mostly considered in the financial sector and much attention is not given to it in terms of energy consumption.

Today, amidst increasing energy cost, depletion of fossil fuels and environmental concerns, there arise compelling reasons for SMEs to focus on energy efficiency in order to stay in business and be competitive. This research looks at energy use practices of SMEs, their energy related decisions and how energy management can help alleviate some of their business challenges.

\subsection{Resource Efficiency}

Global resources are quantifiable and measurable. This implies that, global resources are exhaustible over a given period of time. It is therefore important to ensure the rational and effective use of resources so that wastage can be reduced to the barest minimum to save the environment from adverse effects. A potential response to this challenge is the concept of resource efficiency. The effective use of resources such as minerals, energy, water, raw materials etc. will lead to sustainability.

Resource efficiency, according to Waste and Resources Action Programme (WRAP), can be defined as using natural resources in the most effective way, as many times as possible, while minimising the impact of their use on the environment [3]. Resource efficiency is not only for environmental concern, but also a good business initiative that has the potential of improving efficiency and saving cost in doing business.

Resource efficiency are generally measured in terms of the percentage of purchased raw materials to finished product [4]. Most at times, smaller percentage of material input in processes end up as a finished product, which presupposes that higher percentage of input materials come out as waste. Global energy, whether renewable or non renewable constitutes a resource and therefore ensuring energy efficiency, which is partly singled out in this research for study. Energy efficiency is one of the areas that can ensure effective resource planning and it is highly commendable when energy efficiency is integrated in resource planning to attain sustainability.

\subsection{Commercial Sector Investment in Energy Efficiency}

Efficiency gap is one factor that appears in many publications on commercial sector energy policy. There are significant gaps between the current and optimum levels of energy efficiency [5]. Many publications have characterized these gaps as neoclassical economics and institutional or behavioural economics summarised in literature, including $[6,7,8]$.

\subsection{Barriers and Drivers of Energy Efficiency in SMEs}

Barriers to energy efficiency have been investigated by 112 SMEs in the UK alone [9]. Manufacturing firms in the UK have said they had embraced energy efficiency policies because they were big consumers of electricity. Other stakeholders have done some research on energy efficiency including: Trianni et al. [10] who studied 48 manufacturing firms in Northern Italy; Trianni et al. [11] who also studied 222 manufacturing SMEs in Northern Italy; and Hrovatin et al. [12] who studied the factors impacting the decision to invest in energy-efficient and clean technologies. Industrial SMEs in Zimbabwe have also reviewed challenges in energy efficiency by Muzamwese [13].

\section{Materials and Methods}

Following the works of Paramonova and Thollander [14] and Trianni et al. [11], the study applied the use of energy auditing to identify energy conservation opportunities in the various SMEs that were studied. Also, Ackah [7] and Muzamwese [13] focused on the barriers of energy efficiency of SMEs in rural areas on energy related decision making using energy auditing to identify energy conservation opportunities to reduce energy cost and maximize profit in both rural and urban areas in the Sunyani Municipality.

The research objectives and literature review guided the data collection and their conversion to interview questions (questionnaire) and explains how the selected SMEs were interviewed. Energy Audit was the method used to identify the energy conservation opportunities in the various SMEs studied.

\subsection{Area of Study}

The area of study is the Sunyani Municipality located in the Brong-Ahafo Region of Ghana. Most of the citizens in the area reside in the city of Sunyani and the Sunyani District has a growth rate of three-point seven six percent (3.76\%) [15].

The municipality has a total land area of 829.3 square kilometres (320.1 square miles). There are 18 towns and the capital city, is Sunyani. According to the National Board for Small Scale Industries (NBSSI), there are four hundred and three (403) registered enterprises in the Sunyani Municipality as at January, 2010.

\subsection{Use of Quantitative and Qualitative Techniques}

The research focused on developing an understanding of the context within which businesses made their decisions when it comes to energy consumption. To develop this contextual understanding, there was the need to use semi-structured interviews with business owners and their employee (s) within the municipality.

The semi-structured form of interview was used for the data collection. The interviewer maintained discretion to follow up leads with the interview guide being a set of clear instructions [16].

\subsection{Sampling}

Collecting and gaining data from all available sources is impossible. Therefore, sampling techniques provision helps to minimise the data needed by considering sub-group rather than all possible cases or elements [17].

Regarding the purpose of this research, the stratified 
random sampling and purposive sampling technique was used. Stratified random sampling enables the researcher to divide the population into smaller groups known as strata and the strata are formed based on members' shared attributes or characteristics. It ensures that, data is taken from the different types of groups which can be used in statistical analyses.

For this study, purposive sampling was used because the organisations selected were small and medium enterprises (SMEs) in the Sunyani Municipality. The study categorizes small enterprises as those with 5-29 employees and medium-sized enterprises as those with 30-99 employees [18].

\subsubsection{Selection Criteria of Sample}

The selection criteria used was that, the SME had to be a registered business in the municipality. They were then grouped and categorized according to location, type, and size of business.

\subsubsection{Sample Size}

The sample size was determined using the Krejcie and Morgan sampling technique table [19]. In all, a sample size of 200 businesses were selected based on availability, willingness to participate, time and financial constraint.

\subsection{Energy Audit}

For successful identification of energy reduction strategies for the various SMEs studied, audit of these businesses was conducted using the ASHRAE method of auditing a facility. An energy audit "involves an analysis of a facility to determine the forms of energy used, the quantities and costs of the various forms of energy used, the purposes for which the energy is being used, and the identification of energy conservation opportunities" [20].

The ASHRAE energy audit process is structured into three levels or phases of audit of increasing complexity and requires time and cost to execute. The levels are: 1) Walkthrough Survey; 2) Energy Survey and Analysis; and 3) Detailed Analysis of Capital-Intensive Modifications.

Majority of the requirements of a level 2 audit were undertaken in this work (including level 1 requirements). The overall outcome of the audit was used to develop a list of recommendations of energy efficiency measures that can be implemented in providing potential savings.

During the walkthrough process, the following information was collected: i) major energy consuming services in the SMEs studied such as Heating Ventilation and Air Conditioning (HVAC), fan, fridge, hair dryer, iron and lighting; ii) Rated loads (from equipment nameplates); and iii) Estimated equipment/building usage (based on respondent's knowledge).

Through the walkthrough survey, huge numbers of lighting bulbs were recorded in the businesses of study with most of the bulbs being left on during the day. This practice offers an energy saving potential and hence such places with savings potential in the various firms were studied. The appliances used by the SMEs were also observed during their operating hours to ascertain their state in the view of coming out with efficiency approaches possible to reduce their energy consumption.

\subsection{Analysis of Energy Using Systems}

Once the equipment data had been collected, it was collated into three end use categories: HVAC, lighting and auxiliary (plug in loads such as computers, fridges, etc.). Largely, this process involved calculations based on the operating loads of equipment and the daily hours of operation to determine the energy consumed in a day and half a year.

The following formulas were used in calculating the energy consumption and operating cost of the appliances studied:

Energy Demand $(\mathrm{kWh})=$ Wattage $(\mathrm{W}) \times$ Operating hours $(\mathrm{H})$ $\times$ Quantity of appliance

Cost of energy consumption $(\mathrm{GH} \phi)=$ Energy Demand $(\mathrm{kWh})$ $\times$ Cost of electricity per $\mathrm{kWh}$

where:

energy demand is the amount of energy consumed by the company;

the wattage is the power rating of the appliance used in the facility;

operating hours is the number of hours the appliance is used in a day; and

the quantity is the number of the same appliance used in the facility.

The cost of electricity was obtained from electricity tariffs publication available at the Electricity Company of Ghana website.

Through the survey of these SMEs, energy reduction or efficiency opportunities were developed. This was aimed at reducing the energy consumption of the SMEs with the identified energy reduction strategies. The cost factor was also considered ensuring a cost-effective method of reducing the energy use.

In generating the list of energy reduction opportunities, the following aspects were taken into consideration:

Observation of equipment specification, the current state and any performance data readily available;

Operating schedules of the equipment in the facility; and

Behavioral attitudes towards energy usage.

\subsection{Data Collection}

This section discusses the collection of data in two forms, primary and secondary data collection. The primary data was collected through observation and interviews using questionnaire. The essence of using observation is to minimize the impact of social desirability biases, that is, when respondents report things that may not be the fact on the ground or reflect actual behaviour [21]. The secondary data collected include recording of nameplates of energy consuming equipment and electricity bill receipts. This data was useful with regards to energy auditing.

\subsubsection{Field Interviews}

The research required that field interviews be conducted with the SMEs for the necessary information to be gathered. Such information was obtained by face to face interviews and administering questionnaires to the employers (decision 
makers) and employees on the subjects involved. Before embarking on the main data collection, a pilot study was conducted to address any deficiencies in the questionnaires design before time and resources were expended on a large scale. Some interview data were also captured either by audio recording or interviewer notes, based on respondent's preference, ambient noise, and other factors.

One of the main instruments used for the collection of primary data was the questionnaire. The confidentiality of the data given by the respondents were guaranteed and that they were to be used for the purpose of the research only.

\subsubsection{Secondary Data}

Data pertaining to energy consumption, utility bills, occupancy rate etc. were collected and collated to obtain the status of energy consumption in relation to available equipment and the duration of usage. Equipment used in SMEs was compared to standard equipment consumption rates to ascertain the achievable savings.

\subsection{Data Analysis}

The analysis of the data was handled under specific objectives of the research. It involved the use of analysis software for the data analysis. The data analysis involved in the research were in the following parts, namely: statistical analysis, financial analysis and energy management approach.

The statistical and financial analysis involved the use of analysis software such as SPSS and Microsoft Excel. They were applied on the field data for retrieving relevant information. The energy management approach involved the process of analyzing SMEs current energy consumption, how they purchase energy, available options, costs and benefits.

\section{Results and Discussions}

\subsection{Analysis of Questionnaire}

This section presents the results of the data obtained from the questionnaire during the survey. The responses that emerged from the questionnaire highlighted the energy related decisions of SMEs in the Sunyani Municipality.

Table 1 shows some of the characteristics of SMEs by geographic location. From the Table 1, the Sunyani Township recorded the highest SMEs with a percentage of $27.5 \%$ representing 44 SMEs interviewed. South Ridge and Nkrankrom recorded the least number of SMEs interviewed. This was because most of the SMEs in these areas were not registered or were not connected to the national grid and also less populated.
The industry distribution is summarized in Figure 1.

Figure 1 highlights the industry categorization of the respondents. Because trading is predominant in the Sunyani Municipality, the trading industry provided the highest number of respondents, followed by the arts and artisan industry. The trading industry recorded $49.38 \%$ and consist of boutiques, cosmetic shops, fabric shops, hardware shops, dealers of home and office equipment and provision shops. The arts and artisan industry which recorded $34.38 \%$ also consist of hair dressing saloons, barbering shops, dress making shops and photo studios. The servicing industry which recorded the least, $(6.88 \%)$ of the total responses consists of auto repair shops, printing and photocopy shops and architect consulting shops.

Table 1. Distribution of SMEs by Location.

\begin{tabular}{lll}
\hline Location & Number of SMEs & Percentage of Total SMEs (\%) \\
\hline Sunyani & 44 & 27.50 \\
Zongo & 16 & 10.00 \\
Area 2 & 13 & 8.13 \\
Estate & 6 & 3.75 \\
Baakoniaba & 8 & 5.00 \\
South Ridge & 4 & 2.50 \\
Airport Area & 5 & 3.13 \\
Nkwabeng & 7 & 4.38 \\
Abesim & 30 & 18.80 \\
New Dormaa & 16 & 10.00 \\
Atronie & 7 & 4.38 \\
Nkrankrom & 4 & 2.50 \\
Total & 160 & 100.00 \\
\hline
\end{tabular}

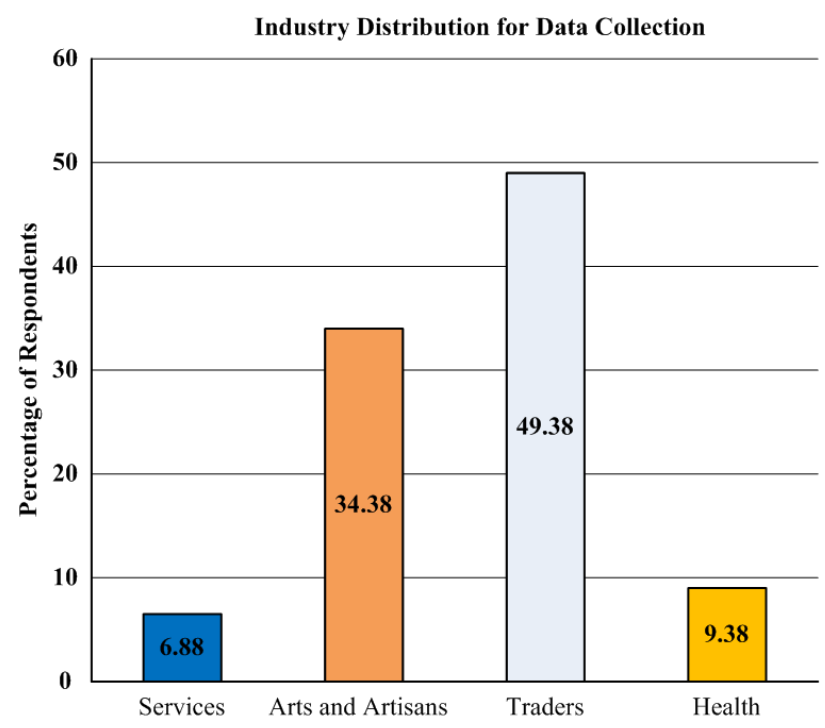

Figure 1. Industry Distribution for Data Collection.

Table 2. Number of Employees of SMEs Interviewed.

\begin{tabular}{llll}
\hline No of employees & Number of Respondents & Percentage (\%) & Category \\
\hline $1-5$ & 128 & 80.00 & Micro Enterprise \\
$6-29$ & 30 & 18.75 & Small Enterprise \\
$30-99$ & 2 & 1.25 & Medium Enterprise \\
Total Response & 160 & 100 & \\
\hline
\end{tabular}

128 SMEs interviewed were micro enterprises, representing $80 \%$ and $18.75 \%$ representing 30 SMEs were small scale, whilst $1.25 \%$ of SME interviewed were medium size (30-99) indicated in Table 2. The findings indicated that, the number 
of employees were 1 to 99 , making them fall within the range accepted as SMEs.

The six and seventh item on the questionnaire was to find out the approximate monthly expenditure on electricity and the number of times power was purchased. The results in Table 3 showed that, $63.75 \%$ (102) of the total SMEs purchased power below GH $\varnothing 100$ a month, $21.25 \%$ (34) of the respondents purchased an amount between $\mathrm{GH} \phi$ (101 to 200) and $15 \%$ of the respondents purchased power above GH $\notin 200$ in a month.

Table 3. Monthly Expenditure on Electricity.

\begin{tabular}{lll}
\hline Monthly Expenditure & Number of Respondents & Percentage (\%) \\
\hline below GH $\varnothing 100$ & 102 & 63.75 \\
GH $\varnothing 101-200$ & 34 & 21.25 \\
above GH $\varnothing 200$ & 24 & 15.00 \\
Total Respondents & 160 & 100 \\
\hline
\end{tabular}

\subsection{Analysis of Energy Auditing}

This section discuss appliances used by some selected SMEs based on their high energy demand and also based on the industry in which they were categorized into. The wattage of each appliance was considered and their estimated operating hours multiplied by the quantity of each appliance which determines the electrical energy demand per day in watt-hours. This helps give a general idea of energy consumption of the various SMEs in the Sunyani Municipality and identify energy conservation opportunities which reduce their energy consumption.

\subsubsection{Appliance Usage in Some Selected SMEs}

Table 4 shows the appliances used by a College Administration Block in their daily operations. It shows that, the appliance with the highest energy demand is the Air Conditioner (AC) and followed by lighting. A 3-star fridge is the least consuming appliance in the facility.

Table 4. Appliances and Energy Demand of a College Administration Block.

\begin{tabular}{lllll}
\hline Appliance & Wattage & Quantity & $\begin{array}{l}\text { Operating } \\
\text { Hours }\end{array}$ & $\begin{array}{l}\text { Energy } \\
\text { Demand (Wh) }\end{array}$ \\
\hline Printer & 80 & 2 & 2 & 320 \\
PC & 130 & 2 & 9 & 2340 \\
Laptop & 60 & 9 & 6 & 3240 \\
AC & 1270 & 4 & 5 & 25400 \\
Fan & 100 & 4 & 2 & 800 \\
CFL & 40 & 10 & 9 & 3600 \\
3 Star Fridge & 34 & 1 & 6 & 204 \\
Total & & & & 35904 \\
\hline
\end{tabular}

Similarly, salient appliances, their wattage, quantity, operating hours, and energy demands were calculated for various SMEs and their corresponding total energy demands determined as shown in Table 5 per day. The electrical demands in these SMEs are high due to the following reasons:

Increased number of bulbs. Example: the fabric shop has a total of 10 bulbs;

High rating of bulbs and other appliances used in the facilities. Example: Most of the bulbs are $105 \mathrm{~W}$ and $85 \mathrm{~W}$. the $\mathrm{AC}$, fan and iron also had high ratings;
Low efficiency of appliances used. Majority of the equipment used have 1-star or no star labelling. Example: the AC, photocopy machine, the iron; and

The use of Second Hand and Home use equipment. Example: the hair dryer used in saloons, the fridges used by the provision shops, the irons used in the tailoring shop.

Table 5. Total Electric Demand of selected SMEs.

\begin{tabular}{ll}
\hline Selected SME & Energy Demand (kWh) \\
\hline College Administration Block & 35.90 \\
Photocopy and Printing Shop & 38.48 \\
Fabric Shop & 10.90 \\
Provision Shop & 21.81 \\
Clothes Boutique & 12.84 \\
Hair Boutique & 11.35 \\
Pharmacy Shop & 27.67 \\
Medical Laboratory & 25.13 \\
Hair Dressing Saloon & 17.32 \\
Tailoring Shop & 41.66 \\
Barbering Saloon & 8.44 \\
\hline
\end{tabular}

The increase in energy demand is however, attributed to the increased number of lighting bulbs with high ratings in these facilities together with other operating devices. This presupposes that, lighting has a major potential for saving energy for these SMEs.

\subsubsection{Lighting Load in Some Selected SMEs}

One major thing observed during the walkthrough of the energy audit was the use of light by SMEs for their daily operations. It was observed that, majority of the respondents could not do away with lighting in their day to day activities and the bulbs were mostly on during the operational hours of the company, even during sunny days. Majority of the SMEs (72.5\%) interviewed use Compact Fluorescent Lamps (CFL), which is termed energy saving but the wattage of the bulbs used by these SMEs is quite alarming.

The lighting consumption of the various selected SMEs are presented in Table 6. The fabric shop dominates in the trading industry, followed by the provision shop. The fabric shop has a high lighting demand because of increased number of bulbs (10) and each has a rating of $105 \mathrm{~W}$. The clothes boutique recorded the least in lighting demand because this facility uses LED bulbs, which consumes less (5 W each).

In the health industry, the pharmacy shop and medical laboratory was the SME studied. The pharmacy shop consumes more than the medical laboratory because the pharmacy only had CFL bulbs, each with a rating of $85 \mathrm{~W}$ but the medical laboratory uses both CFL and fluorescent lamp, each with a rating of $85 \mathrm{~W}$ and $32 \mathrm{~W}$ respectively. This shows that, further reducing the rating of bulbs used in the facility help reduce energy consumption.

In the service industry, the printing and photocopying shop has low lighting demand (less than $1 \mathrm{kWh}$ ) but the rating of the bulbs used is very high $(105 \mathrm{~W})$. The increase in number of bulbs used in the college administration block constitute the high lighting demand. It was observed that, each office had 2 bulbs and each bulb had a rating of $40 \mathrm{~W}$. Therefore, reducing the number of bulbs in some office space and using bulbs with 
low ratings will help reduce the lighting load in this facility. The hair dressing and barbering saloon have similar lighting load demand. The tailoring shop has the highest demand because of the long operating hours of the bulbs, high rating and increase in the number of bulbs used. Providing bulbs that can perform the same function but with low ratings will reduce the energy cost of this facility.

Table 6. Lighting Demand in Selected SMEs.

\begin{tabular}{lll}
\hline Industry & SME & $\begin{array}{l}\text { Lighting } \\
\text { Demand (kWh) }\end{array}$ \\
\hline Services & College Administration Block & 3.60 \\
& Photocopy and Printing Shop & 0.84 \\
Trading & Fabric Shop & 10.23 \\
& Provision Shop & 6.06 \\
& Clothes Boutique & 3.54 \\
\multirow{3}{*}{ Health } & Hair Boutique & 7.35 \\
& Pharmacy Shop & 5.10 \\
Arts and Artisans & Medical Laboratory & 4.79 \\
& Hair Dressing Saloon & 3.36 \\
& Tailoring Shop & 7.56 \\
& Barbering Saloon & 3.15 \\
\hline
\end{tabular}

\subsubsection{Various Use of Electrical Energy}

Table 7 shows the total amount of energy used for different purposes in the facilities of some SMEs when the energy audit was carried out.

The results show differences in electrical demand among SMEs due to firm size, energy expenditure, complexity of production, and monthly turnover. Therefore, comparing the electrical demand of these SMEs will be incompatible. The SMEs were therefore, grouped into their respective industries to promote industrial energy efficiency.

Table 7. Various Use of Electrical Energy.

\begin{tabular}{llll}
\hline \multirow{2}{*}{ SME } & \multicolumn{3}{l}{ Energy Demand (kWh) } \\
\cline { 2 - 4 } & HVAC & Lighting & $\begin{array}{l}\text { Other } \\
\text { Plug-ins }\end{array}$ \\
\hline College Administration Block & 26.20 & 3.60 & 6.104 \\
Photocopy and Printing Shop & 24.56 & 0.84 & 13.08 \\
Fabric Shop & 0.33 & 10.23 & 0.337 \\
Provision Shop & 1.50 & 6.06 & 14.250 \\
Clothes Boutique & 6.80 & 3.54 & 2.500 \\
Hair Boutique & 1.50 & 7.35 & 2.500 \\
Pharmacy Shop & 16.69 & 5.10 & 5.880 \\
Medical Laboratory & 13.65 & 4.79 & 6.686 \\
Hair Dressing Saloon & 0.78 & 3.36 & 13.184 \\
Tailoring Shop & 1.60 & 7.56 & 32.498 \\
Barbering Saloon & 2.60 & 3.15 & 2.690 \\
\hline
\end{tabular}

It was observed that, heating, ventilation and air-conditioning (HVAC) leads in the consumption of the electrical energy in the service industry, followed by other plug-ins. HVAC takes majority of the electrical energy in the pharmacy and medical laboratory. The energy consumption of other plugins from the tailoring shop dominates in the arts and artisans' industry. Lighting, which offers a potential energy reduction option was the most common strategy realized in the SMEs studied. The lighting load can easily be brought down to reduce usage in these facilities.

\subsection{Option Considered as Strategy for Reducing Energy}

The lighting load, which was considered as an energy conservation opportunity was analysed to show how it is significant in terms of capital costs, and running costs. This option was analysed and evaluated to convince the SMEs take a decision on the implementation of strategy in energy reduction to reduce waste.

Based on the energy audit conducted, one of the ways of cutting down energy consumption in the facilities studied is by using efficient appliances and one major consumer is the lighting system. Using efficient lamps such as LED lamps will cut down the lighting load in these SMEs. The analysis in Table 8 show significant difference in the replacement of lamps.

Table 8 gives the estimate of LED lamps consumption if they are used instead of fluorescent and CFL. The consumption of the LED is compared with consumption by fluorescent and CFL used.

Table 9 shows the amount of energy consumed by the LED and T12+CFL lamps and their respective cost of energy daily. The table shows that, the operating cost of CFL and T12 lamps are expensive as compared to LED lamps. The cost per energy consumption was $\mathrm{GH} \not 0.735$ per kWh of electricity consumed as at July, 2019 by the Public Utilities Regulatory Commission of Ghana.

The estimated cost of consumption of these lamps is calculated for a 6 month period as shown in Table 10. With the replacement of the T12 and CFL bulbs with LED bulbs, significant amount of energy and cost will be saved. These calculations were on an assumption that the bulbs had equal hours of usage in the days of the year in each firm respectively. Table 10 shows cost analysis on capital cost of CFL and T12 bulbs and their running cost as well as that of the LED bulbs in the various SMEs in a 6 month period.

In the college administration block, the total initial capital cost of the $15 \mathrm{~W}$ LED bulbs is higher than that of the $40 \mathrm{~W}$ CFL bulbs used, but the running cost of CFL is higher than that of the LED. By switching to LED, a savings of GHC193 is made in a 6 month period. Saving were made in all the selected SMEs considered as shown in Table 11.

Table 8. Comparison of LED lamp with T12 Fluorescent and CFL.

\begin{tabular}{|c|c|c|c|c|c|c|c|c|}
\hline \multirow{2}{*}{ SME } & \multicolumn{4}{|c|}{ Wattage (W) } & \multirow{2}{*}{ T12 } & \multirow{2}{*}{$\begin{array}{l}\text { Small } \\
\text { CFL }\end{array}$} & \multicolumn{2}{|c|}{ Energy Consumption (kWh/Day) } \\
\hline & LED & T12 & Small CFL & Big CFL & & & LED & CFL+T12 \\
\hline College Administration Block & 15 & & 40 & & 10 & 9 & 1.35 & 3.60 \\
\hline Photocopy and Printing Shop & 15 & & & 105 & 2 & 4 & 0.12 & 0.84 \\
\hline Fabric Shop & 30 & & 85 (6 pcs) & 105 (4 pcs) & 10 & 11 & 3.30 & 10.23 \\
\hline Provision Shop & 15 & $32(2$ pcs $)$ & 85 (4 pcs) & & 6 & 15 & 1.35 & 6.06 \\
\hline Clothes Boutique & 15 & & 85 & & 4 & 10 & 0.60 & 3.40 \\
\hline Hair Boutique & 30 & & & 105 & 7 & 10 & 2.10 & 7.35 \\
\hline
\end{tabular}




\begin{tabular}{|c|c|c|c|c|c|c|c|c|}
\hline \multirow{2}{*}{ SME } & \multicolumn{4}{|c|}{ Wattage (W) } & \multirow{2}{*}{ T12 } & \multirow{2}{*}{$\begin{array}{l}\text { Small } \\
\text { CFL }\end{array}$} & \multicolumn{2}{|c|}{ Energy Consumption (kWh/Day) } \\
\hline & LED & T12 & Small CFL & Big CFL & & & LED & CFL+T12 \\
\hline Pharmacy Shop & 15 & & 85 & & 5 & 12 & 0.90 & 5.10 \\
\hline Medical Laboratory & 15 & 32 (3 pcs) & 85 (4 pcs) & & 7 & 11 & 1.16 & 4.79 \\
\hline Hair Dressing Saloon & 30 & & & 105 & & & 0.96 & 3.36 \\
\hline Tailoring Shop & 30 & & & 105 & & & 2.16 & 7.56 \\
\hline Barbering Saloon & 30 & & & 105 & & & 0.90 & 3.15 \\
\hline
\end{tabular}

Table 9. Estimated Cost of Consumption of LED and T12+CFL lamps per day.

\begin{tabular}{lllll}
\hline \multirow{2}{*}{ SME } & \multicolumn{2}{l}{ Energy Consumption (kWh/Day) } & Cost (GHC) & CFL+T12 \\
\cline { 2 - 5 } & LED & CFL+T12 & LED & 1.02 \\
\hline College Administration Block & 1.35 & 3.60 & 0.09 & 0.63 \\
Photocopy and Printing Shop & 0.12 & 0.84 & 2.49 & 7.71 \\
Fabric Shop & 3.30 & 10.23 & 1.02 & 4.56 \\
Provision Shop & 1.35 & 6.06 & 0.45 & 2.56 \\
Clothes Boutique & 0.60 & 3.40 & 1.58 & 5.54 \\
Hair Boutique & 2.10 & 7.35 & 0.68 & 3.84 \\
Pharmacy Shop & 0.90 & 5.10 & 0.87 & 3.61 \\
Medical Laboratory & 1.155 & 4.79 & 0.72 & 2.53 \\
Hair Dressing Saloon & 0.96 & 3.36 & 1.63 & 5.69 \\
Tailoring Shop & 2.16 & 7.56 & 0.68 & 2.37 \\
Barbering Saloon & 0.90 & 3.15 & & \\
\hline
\end{tabular}

Table 10. Estimated Half a Year Cost of Consumption of Lamps.

\begin{tabular}{|c|c|c|c|c|c|}
\hline \multirow{2}{*}{ SME } & \multicolumn{2}{|c|}{ Energy Consumption (kWh/6 Months) } & \multicolumn{2}{|c|}{ Cost (GH\$) } & \multirow{2}{*}{ Operating Cost Saving } \\
\hline & LED & CFL+T12 & LED & CFL+T12 & \\
\hline College Administration Block & 1.35 & 3.60 & 1.02 & 2.71 & 223.70 \\
\hline Photocopy and Printing Shop & 0.12 & 0.84 & 0.09 & 0.63 & 84.60 \\
\hline Fabric Shop & 3.30 & 10.23 & 2.49 & 7.71 & 814.27 \\
\hline Provision Shop & 1.35 & 6.06 & 1.02 & 4.56 & 553.42 \\
\hline Clothes Boutique & 0.60 & 3.40 & 0.45 & 2.56 & 329.00 \\
\hline Hair Boutique & 2.10 & 7.35 & 1.58 & 5.54 & 616.87 \\
\hline Medical Laboratory & 1.155 & 4.79 & 0.87 & 3.61 & 427.11 \\
\hline Hair Dressing Saloon & 0.96 & 3.36 & 0.72 & 2.53 & 282.00 \\
\hline Tailoring Shop & 2.16 & 7.56 & 1.63 & 5.69 & 634.50 \\
\hline Barbering Saloon & 0.90 & 3.15 & 0.68 & 2.37 & 305.05 \\
\hline
\end{tabular}

Table 11. Estimated Half a Year Cost Savings when CFL+T12 are Replaced with LED Lamps.

\begin{tabular}{|c|c|c|c|c|c|c|c|}
\hline \multirow{2}{*}{ SME } & \multicolumn{2}{|c|}{ Operating Cost (GHC)/ 6 Months } & \multicolumn{2}{|c|}{ Total Cost of Bulbs } & \multicolumn{2}{|c|}{ Overall Cost } & \multirow{2}{*}{$\begin{array}{l}\text { Cost Savings/6 } \\
\text { Months (GHC) }\end{array}$} \\
\hline & LED & CFL+T12 & LED & CFL+T12 & LED & CFL+T12 & \\
\hline College Administration Block & 1.35 & 3.60 & 1.02 & 2.71 & 234.2 & 427.9 & 223.70 \\
\hline Photocopy and Printing Shop & 0.12 & 0.84 & 0.09 & 0.63 & 34.1 & 168.7 & 84.60 \\
\hline Fabric Shop & 3.30 & 10.23 & 2.49 & 7.71 & 587.8 & 1522.0 & 814.27 \\
\hline Provision Shop & 1.35 & 6.06 & 1.02 & 4.56 & 218.6 & 850.1 & 553.42 \\
\hline Clothes Boutique & 0.60 & 3.40 & 0.45 & 2.56 & 110.5 & 519.5 & 329.00 \\
\hline Hair Boutique & 2.10 & 7.35 & 1.58 & 5.54 & 386.8 & 1108.6 & 616.87 \\
\hline Pharmacy Shop & 0.90 & 5.10 & 0.68 & 3.84 & 172.0 & 841.4 & 569.42 \\
\hline Medical Laboratory & 1.155 & 4.79 & 0.87 & 3.61 & 205.7 & 709.8 & 427.11 \\
\hline Hair Dressing Saloon & 0.96 & 3.36 & 0.72 & 2.53 & 192.8 & 534.8 & 282.00 \\
\hline Tailoring Shop & 2.16 & 7.56 & 1.63 & 5.69 & 373.8 & 1098.3 & 634.50 \\
\hline Barbering Saloon & 0.90 & 3.15 & 0.68 & 2.37 & 222.0 & 602.1 & 305.05 \\
\hline
\end{tabular}

\section{Conclusions}

A descriptive analysis was used to examine the barriers and energy efficiency indicators. Energy audit method was applied in the various SMEs to help identify energy reduction opportunities that can help reduce the energy consumption in SMEs. SMEs in the Sunyani Municipality have reduced their energy consumption attributable to the increase in electricity prices. The least in the ranking factors was energy efficiency. Energy efficiency led to profitability through reduced electricity bills, alluded to by $84 \%$ of the respondents. Lack of information was the most important barrier on energy efficiency practices. The practices employed: such as turning off electrical appliances when not in use; using new electrical appliances; and using fewer appliances were approaches embraced by SMEs in the Sunyani Municipality. The results of the energy audit revealed that, majority of SMEs do not have efficient lighting system in their premises. This is due to lack of 
technical know-how and less education of efficient lighting system, thereby having to pay for more in terms of electricity bills due to high ratings of bulbs and high number of bulbs and other equipment used in the facilities.

\section{Recommendations}

The study recommends the following:

The Ghana Energy Commission intensify its energy efficiency education and re-introduce the 'old freezer for a new freezer' programme to cover other common appliances used by SMEs (e.g. air conditioners);

Associations and organizations such as churches and mosques be used to train SMEs on energy efficiency measures;

Upgrade old equipment and machinery with modern ones will drastically reduce energy consumptions;

Replacement of inefficient equipment;

Implement Employee Awareness Program;

Implement an energy management plan; and

Energy policy programs towards SMEs should primarily target support processes (heating, ventilation, lighting, etc.) in regard to improved energy efficiency in SMEs.

\section{References}

[1] Hampton, S. E., McGowan S., Ozersky T., Virdis S. G. P., Vu T. T., Spanbauer T. L., Kraemer B. M., Swann G., Mackay A. W., Powers S. M., Meyer M. F., Labou S. G., O'Reilly C. M., DiCarlo M., Aaron W. E. Galloway A. W. E., and Fritz S. C. (2018), "Recent ecological change in ancient lakes", Limnology and Oceanography, Vol 63, Issue 5, pp. 2277-2304.

[2] International Energy Agency (IEA) (2015). Accelerating Energy Efficiency in Small and Medium-sized Enterprises. Powering SME's to catalyse economize growth, $81 \mathrm{pp}$.

[3] Waste and Resources Action Programme (WRAP), U. K. WRAP Material change for better environment. Retrieved June 3, 2011, from WRAP UK web site: www.wrap.org.uk/wrap_corporate/about_wrap/resource_effici ency.html.

[4] Allwood J. M., Ashby M. F., Gutowski T. G., Worrell E. (2013), "Material efficiency: providing material services with less material production." Philosophical Transactions Series A, Mathematical, Physical, and Engineering Sciences, vol. 371, 1986 20120496, doi: 10.1098/rsta.2012.0496.

[5] Hirst, E. and M. Brown. (1990), "Closing the efficiency gap: barriers to the efficient use of energy", Resources, Conservation and Recycling, 3 (4): pp. 267-281.

[6] Payne, C. T. (2006). Energy Consumption Behaviour in the Commercial Sector: An Ethnographic Analysis of Utility Bill Information and Customer Comprehension in the Workplace.

[7] Ackah, I. (2017, March). Analysis of Energy Efficiency
Practices of SMEs in Ghana: An application of Product Generational Dematerialisation. Africa Centre for Energy Policy. Retrieved from https://mpra.ub.uni-muenchen.de/77484/.

[8] Johansson, I., Mardan, N., Cornelis, E., Kimura, O., Thollander, P. (2019). Designing Policies and Programmes for Improved Energy Efficiency in Industrial SMEs, Energies, 17 pp.

[9] Bradford, J.; Fraser, E. D. G. (2008), "Local authorities, climate change and small and medium enterprises: Identifying effective policy instruments to reduce energy use and carbon emissions", Corporate Social Responsibility and Environmental Management, Vol 15, Issue 3, pp. 156-172.

[10] Trianni, A., Cagno, E., Worrell, E.; Pugliese, G. (2013). Empirical investigation of energy efficiency barriers in Italian manufacturing SMEs. 49, pp. 444-458.

[11] Trianni, A.; Cagno, E.; Farné, S. (2016). Barriers, drivers and decision-making process for industrial energy efficiency: A broad study among manufacturing small and medium-sized enterprises. Appl. Energy, 162, pp. 1537-1551.

[12] Hrovatin, N.; Dolsak, N.; Zoric, J. (2015). Factors impacting investments in energy efficiency and clean technologies: Empirical evidence from Slovenian manufacturing firms. J. Clean. Prod., 127.

[13] Muzamwese, T. C. (2016). Challenges and opportunities for mainstreaming industrial energy efficiency in small-to-medium-sized industries in Zimbabwe. Wiley Interdiscip. Rev. Energy Environ., 5, pp. 510-518.

[14] Paramonova, S.; Thollander, P. (2016). Ex-post impact and process evaluation of the Swedish energy audit policy programme for small and medium-sized enterprises. J. Clean. Prod. 135, pp. 932-949.

[15] Ghana Statistical Service, 2010 Population and Housing Census, (2012), 15 pp.

[16] Bernard, H. R. (2006). Research Methods in Anthropology: Qualitative and Quantitative Approaches, 4th ed., AltaMira Press; $824 \mathrm{pp}$

[17] Saunders M., Lewis, P. and Thornhill, A. (2007), Research Methods for Business Students, 6th ed., Pearson Education Limited, $604 \mathrm{pp}$.

[18] Toerien, D. F. and Seaman, M. T. (2012), "Regional order in the enterprise structures of selected Eastern Cape Karoo towns", South African Geographical Journal, 94: 2, pp. 137-151.

[19] Krejcie, R. V., and Morgan, D. W., (1970). Determining Sample Size for Research Activities. Educational and Psychological Measurement, 30, pp. 607-610.

[20] Henry H. W., Symonds F. W., Bohm R. A., Gibbons J. H., Moore J. R., Snyder W. T. (2010). Energy Management Theory and Practice, $457 \mathrm{pp}$.

[21] Brace, I. (2008). Questionnaire design: how to plan, structure and write survey material for effective market research, 2nd ed. Kogan Page, 304 pp. 